\title{
Das Wachstum und die Länge des Darmkanals im Kindes- alter, Verhältnis der Darmlänge zur Sitzhöhe.
}

\author{
Von
}

\section{Dr. Karl Terner.}

(Aus der Universitäts-Kinderklinik in Wien. Vorstand: Prof. Dr. C. Pirquet.)

[Eingegangen am 23. Juni 1919.]

Zur Messung der Darmlänge empfiehlt Gundobin den Darm in situ mit einem in Wachs eingeriebenen Zwirnfaden zu messen. Bei Messungen mit anderen Hilfsmitteln sind Differenzen. bis $4 \mathrm{~cm}$ unvermeidlich, da eine ungewachste Schnur nach längerer Benützung länger wird. Ebenso ändert sich die Länge des Darmtraktes bei geblähtem oder leerem Darme, ferner hängt die Zahl davon ab, ob die Messungen an der Kuppe des Darmes oder in der Nähe des Mesenteriums vorgenommen wird. (Differenz $2-4 \mathrm{~cm}$.)

Terenetzki hat an 84 Leichen (im Alter von 2 Wochen bis 18 Jahren) nachgewiesen, daß das Verhältnis der Rumpflänge (gemessen vom Scheitel bis zum Oss. coccyg.) zur Länge des Dünndarmes 1 : 4,2-7,6 beträgt. UUbertragen wir dieses Verhältnis auf Sitzhöhe zur Länge des Dünndarmes, so entsprechen diese Zahlen dem Verhältnis $1: 8,7$ bis 1:12,3.

Debele wies auf Grund von 33 Leichen (1 Monat bis 10 Jahre) nach, daß das Verhältnis der Rumpflänge zur gesamten Darmlänge im Durchschnitte 1 : 15,5 beträgt und folgerte aus seinen Untersuchungen, daß die Länge des Darmes in den ersten 3 Lebensjahren sprunghaft zunehmen, in den folgenden Jahren langsam ansteigen.

In jüngster Zeit hat Pirquet auf Grund des Verhältnisses der Darmlänge zur Sitzhöhe Vorschriften für die Ernährung des Menschen ausgearbeitet, die auch auf den Säugling anzuwenden sind. Die Sitzhöhe ist die Länge des sitzenden Rumpfes, von der Sitzfläche bis zur Scheitelhöhe.

Meine Messungen an 10 Leichen (1 Monat bis 13 Jahre) ergaben, daß die Darmlänge vom 1. Monat bis 4 Jahre rasch zunimmt, hierauf verlangsamt sich die Zunahme, ebenso verhält es sich mit dem S Romanum. Die Darmlänge ist durchschnittlich 10,8 mal größer als die Sitzfläche. 


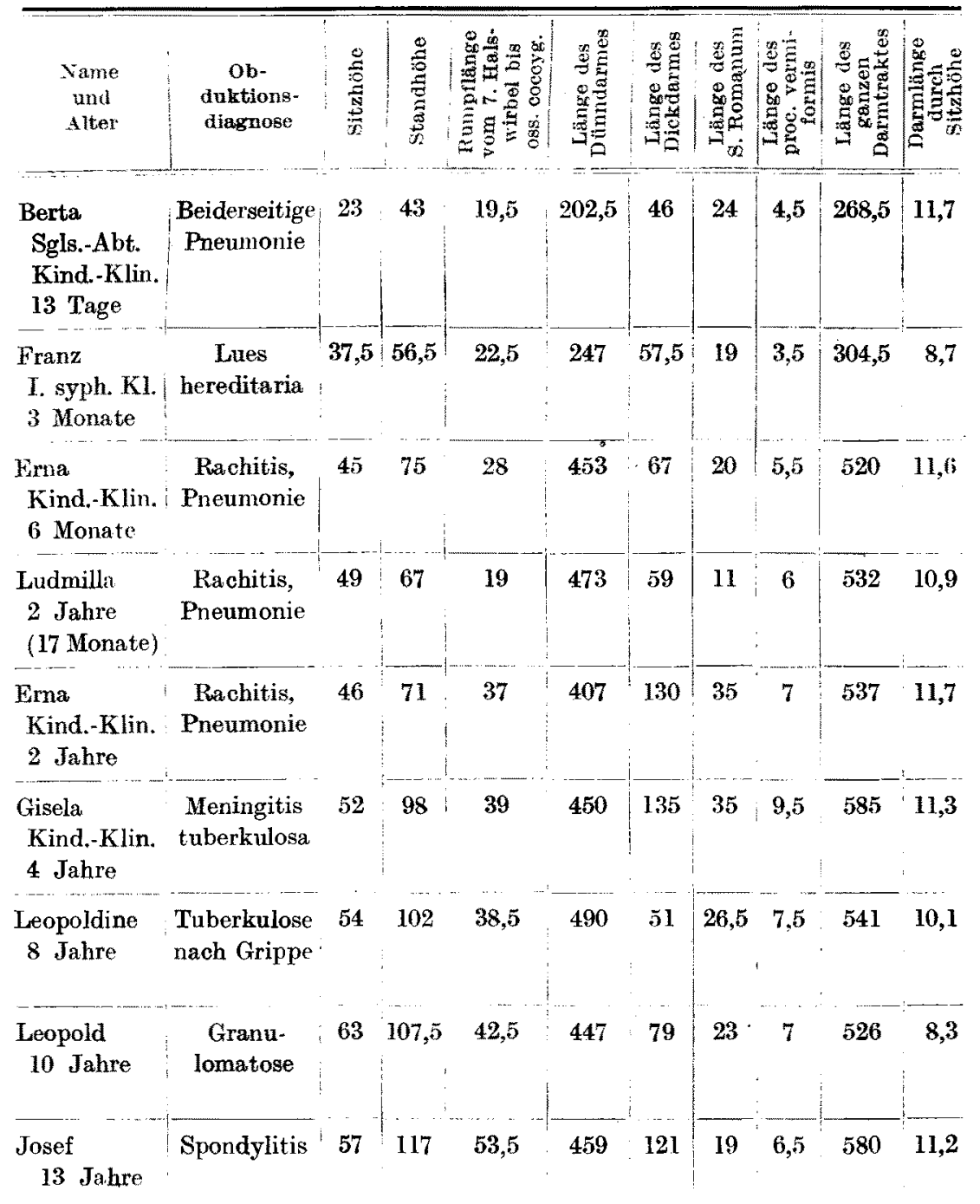

\section{Literaturverzeichnis.}

1. Pirquet, System der Ernährung. I. Teil.

2. Gundobin, die Besonderheiten des Kindesalters.

3. Quetelet, Anthropometrie.

4. Weißenberg, Das Wachstum des Menschen. Stuttgart 1911.

5. West, Gerald Montgomery, Anthropologische Untersuchungen über die Schulkinder in Worcester, Mass. Arch. f. Anthrop. Braunschweig 1894. 